\title{
Airline revenue planning and the COVID-19 pandemic
}

\author{
Ben Vinod
}

\begin{abstract}
Purpose - The static world of flight scheduling where schedules rarely change once published is becoming more responsive with schedule change updates leading up to the departure date due to demand volatility and unpredictable demand patterns. Innovation in cash flow generation will take center stage to operate the business in these uncertain times. Forecasting demand for future flights is a challenge since historical demand patterns are not meaningful which requires a new adaptive robust revenue management approach that monitors key metrics, detects anomalies and quickly takes corrective action when performance targets cannot be achieved.

Design/methodology/approach - The novel COVID-19 pandemic decimated the travel industry in 2020 and continues to plague us with no end in sight. With the steep drop in revenues, airlines need to adapt to a new marketing planning process of scheduling, pricing and revenue management that is more nimble to adapt quickly to changing market conditions. This new approach will continue to be relevant in a post-COVID-19 world during and after economic recovery.
\end{abstract}

Findings - A methodology for airline revenue planning: scheduling, airline pricing and revenue management, has been proposed that will also work in a post-COVID-19 era.

Research limitations/implications - The limitation of the proposed model is that it needs to be applied in practice to determine the true benefits of this novel approach to airline revenue planning.

Practical implications - Flight scheduling will rely more on clean sheet scheduling, schedule revisions and close in refleeting to better match demand to supply. The office of the chief financial officer will have a permanent task force to monitor cash flow and come up with innovative solutions to generate cash flow for liquidity. Adaptive robust revenue management workflows will be integrated into traditional revenue management workflows in the future for competitive advantage.

Social implications - In a post-COVID-19 world it is anticipated that airline business processes will transform to be nimbler and more proactive in making timely decisions at a greater velocity.

Originality/value - The approach to airline revenue planning for scheduling, pricing and revenue management is a new business process that does not exist today at scale in the airline industry.

Keywords COVID-19, Pandemic, Agile schedule changes, Cash flow, Adaptive robust revenue management, Demand forecast accuracy, Performance metrics, Demand levers, Supply levers

Paper type Research paper

\section{Background}

The COVID-19 pandemic that took center stage in December 2019 and escalated to unexpected proportions in 2020 led to a public health crisis on an unprecedented scale. The decimation of the travel industry in 2020 is unprecedented, dwarfing even the First Gulf War, terrorist attacks of September 11, 2001 and the financial crisis of 2008 (RT Question More, 2020). Travel suppliers (airlines, hotels, rental car, cruise lines), intermediaries (Global Distribution Systems, Online Travel Agencies, Wholesalers) and the extended travel value chain of restaurants, theme parks, local attractions and activity providers at tourist destinations are fighting for their survival.

Some countries like New Zealand have effectively dealt with the pandemic with strict border controls, lockdown and social distancing and have been remarkably successful in suppressing the
Ben Vinod is based at Charter and Go, Grapevine, Texas, USA.
Received 28 February 2021

Revised 26 April 2021

Accepted 27 April 2021

(c) Ben Vinod. Published in Journal of Tourism Futures. Published by Emerald Publishing Limited. This article is published under the Creative Commons Attribution (CC BY 4.0) licence. Anyone may reproduce, distribute, translate and create derivative works of this article (for both commercial and noncommercial purposes), subject to full attribution to the original publication and authors. The full terms of this licence may be seen at http://creativecommons.org/ licences/by/4.0/legalcode

The author would like to thank lan Yeoman, Associate Professor of Tourism, Wellington School of Business and Government at Te Herenga Waka-Victoria University of Wellington for giving him the opportunity to participate in the Webinar on July 22, 2020 entitled: Value-based Pricing and Revenue Management in a COVID-19 World, hosted by the Wellington School of Business and Government. This paper is partially based on that presentation. 
virus. The pandemic is a global issue and the return of tourists to New Zealand, like any other country, will be influenced by the global control of the pandemic before international travelers will be allowed to visit to avoid a future breakout. Absence of tough lockdown and strict border crossing controls by ground, air and sea in the early days of the pandemic has resulted in escalating new cases and deaths in Europe and the United States. In the United States, the death toll surpassed half a million on February 22, 2021 (Rattner and Feuer, 2021). More Americans have died from COVID-19 than on the battlefields of First World War, Second World War and the Vietnam War combined. The pandemic has resulted in unpredictable demand patterns and volatility in the travel industry. Corporate travel has all but evaporated and leisure travel among bargain finders remain.

IATA has forecasted that air travel will not recover until 2024 (IATA, 2020). Carriers in North America are estimated to lose $\$ 24$ billion and \$84 billion in collective losses worldwide in 2020 (IATA, 2020; Shapiro, 2020). Major US airlines recorded major losses in 2020 (Reed, 2021). The six largest US airlines lost $\$ 35$ billion dollars in 2020 due to the pandemic. A recent study from the International Civil Aviation Organization (ICAO) found that only 1.8 billion passengers flew in 2020 compared to 4.5 billion passengers in 2019. This resulted in a staggering combined loss of approximately $\$ 370$ billion to airlines (Wood, 2021). Under these circumstances, the focus of every airline chief executive officer and chief financial officer should be on leadership economics-what does it take to survive and win?

To combat the pandemic, several COVID-19 apps have entered the market. The World Health Organization (WHO) has an information app with details about symptoms, real-time notifications by location and the latest news. Various health departments use contact tracing apps to find people who may have come in contact with COVID-19. To make it easier for people to avoid crowds and practice social distancing, online travel company Tripadvisor recently launched a new app, called Crowdfree which utilizes various data sources to highlight crowds at specific neighborhoods and times.

2020 taught us that we must be prepared and resilient for what is thrown at us. With the pandemic in our midst going through second and third waves with more contagious variants in several parts of the world, the travel industry has been impacted on an unprecedented scale. As vaccines are introduced and nations plan on a return to normalcy by 2022, the question that is foremost on the minds of airline executives is - What should be done to ensure survival of the airline in a COVID-19 and post-COVID-19 world?

Survival does not mean that ad hoc and questionable initiatives should dominate decision making. A sound strategy must provide a clear well-defined path to sustained value creation, which implies long-term returns above the cost of capital. The focus should be on initiatives that drive profitable growth, both top line and bottom line.

Over the past four decades revenue management has adapted to changes in technology and new business models in the competitive landscape (Vinod, 2021b) to stay relevant and this will continue in a COVID-19 and post-COVID-19 world. Four areas are recommended for survival in a COVID-19 world: cargo, flight scheduling, airline pricing and revenue management that support airline revenue planning. These concepts will continue to apply in a post-COVID-19 world in which airlines generate revenue opportunistically, are nimbler and make decisions with greater velocity.

\section{Cargo to the rescue}

While consumer-oriented shippers like FedEx, UPS and Amazon have their own dedicated fleets to transport cargo. Passenger airlines have always carried the overflow cargo by loading shipping containers into the belly of the aircraft. This has changed with the decline in passenger traffic and cargo-only flights are pursued by passenger airlines to generate cash flow. With the widespread cancellation of American Airlines flights to Asia and Europe, American introduced cargo-only flights after a 35-year hiatus in March 2020 [1]. Several airlines now operate cargo-only flights to generate cash flow.

PAGE $246 \mid$ JOURNAL OF TOURISM FUTURES $\mid$ VOL. 8 NO. 22022 


\section{Airline schedules}

The schedule defines the airline's primary core product that is offered for sale to corporate and leisure customers. It defines the services offered worldwide and is the first step in the marketing planning process before fare management and revenue management.

Development of an airline schedule falls in the realm of planning, that is meticulously set 6 months12 months in advance based on past performance and market data. In a COVID-19 and postCOVID-19 world, the velocity and continuous feedback loop for schedule development has begun to change with adaptive schedules, something that is not in the vocabulary of schedule planners.

Airlines have invested in making many of their offerings increasingly data-driven with real-time data collection in recent years. Yet, they have not taken the same approach toward schedule development and schedule promotion. Historically, schedule creation has relied on global industry market data sets from multiple sources that may be a few months to several months old without leveraging current booking trends and tactical data. This is about to change as airlines adapt to the new normal of demand patterns that are not stationary.

The pandemic is forcing airlines to rethink their hub and spoke network structure, markets they serve, frequency and composition of the fleet. The impact of the COVID-19 pandemic on airline schedules is illustrated in Tables 1 and 2 which compare 2019 vs 2020 [2].

Table 1 illustrates the scheduled capacity for December 2019 expressed as a percentage of the schedule that was published in September. This is normal operating practice; that a schedule finalized during the planning period four months ago is approximately the same as the schedule observed in December.

Quite in contrast, the planned vs actual schedule data for 2020 looks drastically different, exemplifying the state of the airline industry during the COVID-19 pandemic.

As seen in Table 2, most of these airlines reduced capacity by 50\%, 1-2 months before departure. In a post-COVID-19 era, to adapt faster to market conditions, this rudimentary approach may

\section{Table 1 Planned vs actual scheduled capacity in 2019}

\begin{tabular}{lcccc} 
Airline & September & October & November & December \\
\hline American Airlines & $100.00 \%$ & $99.88 \%$ & $99.77 \%$ & $98.85 \%$ \\
Alaska Airlines & 100.00 & 100.14 & 100.10 & 99.75 \\
Jet Blue & 100.00 & 99.87 & 99.34 & 99.34 \\
Delta Air Lines & 100.00 & 100.23 & 100.20 & 100.20 \\
Frontier & 100.00 & 97.17 & 96.80 & 96.802 \\
Spirit Airways & 100.00 & 100.30 & 97.12 & 97.12 \\
United Airlines & 100.00 & 99.40 & 98.51 & 98.51 \\
Southwest Airlines & 100.00 & $97.07 \%$ & 97.07 & 97.07 \\
Average & 100.00 & 99.26 & 98.49 & 98.46
\end{tabular}

\section{Table 2 Planned vs actual scheduled capacity in 2020}

\begin{tabular}{lcccc} 
Airline & September & October & November & December \\
\hline American Airlines & $100.00 \%$ & $99.56 \%$ & $51.78 \%$ & $51.01 \%$ \\
Alaska Airlines & 100.00 & 100.56 & 60.90 & 60.33 \\
Jet Blue & 100.00 & 95.56 & 51.26 & 48.05 \\
Delta Air Lines & 100.00 & 95.15 & 69.48 & 67.32 \\
Frontier & 100.00 & 72.93 & 55.70 & 54.66 \\
Spirit Airways & 100.00 & 99.17 & 60.37 & 60.05 \\
United Airlines & 100.00 & 95.81 & 48.73 & 46.91 \\
Southwest Airlines & 100.00 & 100.00 & 55.71 & 55.86 \\
Average & 100.00 & 94.84 & 56.74 & 55.52
\end{tabular}


continue to match demand to supply better. Sophisticated network carriers may also rely more heavily on close-in refleeting. This dynamic approach to modifying and promoting schedules requires synchronization with fulfillment partners such as codeshare partners in real-time. A new business process for schedule development can begin with the publication of an overbuilt schedule and trim the schedule closer to the departure date. This, however, introduces challenges with revenue management demand forecasting and inventory control, passenger reaccommodation closer to departure (typically $1-3$ weeks) and crew rostering.

There was also the larger question of whether it made sense to retire older aircraft and simplify the fleet configuration with fewer aircraft types.

The pandemic has also forced airline schedulers to rethink route profitability, develop and publish air schedules from the ground up. This is frequently referred to as clean sheet scheduling that has limited dependence on past schedules. While it is rarely "clean sheet", the idea is to start with a skeleton schedule and build a profitable schedule at the price of schedule consistency because the new schedule may look radically different from what had been published in the past. This gives airlines flexibility with timing, routing, frequency and capacity allocation. Clean sheet scheduling limits the value of historical demand data. Taken to an extreme, clean sheet scheduling can support multi-dimensional decision making simultaneously and eliminate sequential decision making of schedule timetables, fleet assignment and aircraft rotations which is suboptimal.

\section{Cash flow for survival is an opportunity to reinvent the business}

When the revenue pipeline evaporates, conserving cash to keep the lights on is the number one priority. The office of the chief financial officer at companies in the travel value chain must establish a liquidity taskforce focused on managing the cash position. Besides actively managing the day-today cash flow, the taskforce should have a strategic focus to rapidly evaluate scenarios, prioritize initiatives and execute the plan to maintain liquidity. This is not a onetime effort but a continuous process of scenario planning, evaluation and execution of priorities. Figure 1 illustrates this workflow.

Scenario planning must make assumptions about a rapid or prolonged recovery to new spikes in the virus to limit long-term exposure of the business to unfavorable terms. The seismic impact of COVID-19 on travel also gives chief executive officers a window of opportunity to reinvent and reinitialize the business. Reinitialization of the airline business comes along different dimensions: cost containment initiatives and redefinition of the business model for generating revenues.

Cost containment provides a unique opportunity to re-baseline costs including clean sheet budgeting which is the process of rebuilding the operating budget from the ground up to transform the airline to operate efficiently in a post-COVID-19 world. Restructuring charges, asset writedowns and renegotiating existing contracts for more favorable terms with intermediaries and thirdparty vendors should be on the table. For the business model, this is an opportunity to reinvent the airline network, pricing, revenue management and airline operations.

Figure 1 Scenario planning and cash flow management

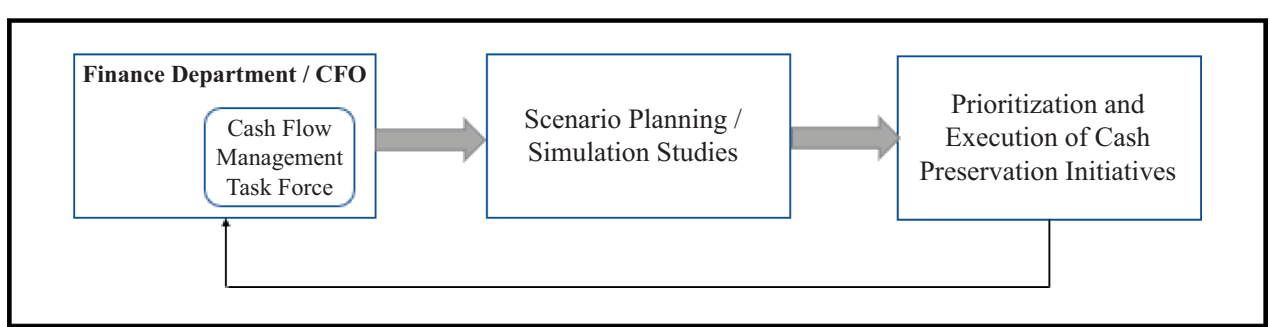

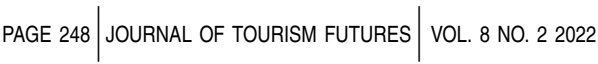




\section{Collaboration with corporations to generate cashflow with airline pricing}

With the COVID-19 pandemic in our midst, airlines are strapped for cash, which is a prerequisite for liquidity and survival before the onset of recovery. The primary airline asset is seat inventory and airlines should consider innovative ways to monetize these seats during the recession. One alternative for airlines is to negotiate with corporations to prepay for travel and offer an additional discount beyond the negotiated corporate discount. Active collaboration between buyers (corporations) and sellers (airlines) should provide mutual benefit to both entities (Vinod, 2020a, b).

Corporations negotiate corporate rates with airlines which are usually a discount off the selling ADT (adult, public fares) in a market. These discounts are not applicable to the entre booking class (Reservation Booking Designator (RBD)) hierarchy, but to the higher valued booking classes. The mechanics of a corporation buying a ticket with a corporate discount are governed by the following ATPCO categories: Category 1 defines who can buy which in this case is the corporation at a discount, Category 15/35 defines who can sell, which is the travel management company (TMC) that manages the corporate travel spend for a corporation and Category 25, the fare by rule corporate discount to a public fare generally with the same rules and restrictions as the public fare. These corporate discounts have an implicit volume of bookings commitment. To survive through the pandemic, airlines should be willing to give steeper discounts that are applicable across all or most booking classes based on ticketed sales volume commitments at the deeper discount. The negotiated volume deep discount represents the maximum seats that can be purchased at the deeply discounted price. Once the booking count threshold has been met, the discount will revert to the standard corporate discount. This will require the airline to keep track of bookings at the deeply discounted price to know when the threshold has been achieved before bookings can revert to the standard corporate discount. Corporate travel is typically booked within 30 days of departure and hence the prepayment to airlines should be made monthly. Such an approach and any related variations should provide an infusion of cash to cash-strapped airlines to continue daily operations. In return for a lump sum prepayment, corporations benefit with deeper discounts on corporate fares. This two-tier corporate discount model is applicable during the pandemic and in a post-COVID-19 world when corporate travel is expected to rebound at a slower pace than leisure travel.

\section{Adaptive robust revenue management}

The focus of robust revenue management amongst academics and practitioners was primarily on the validity of the assumptions made in determining inventory controls using revenue management forecasting and optimization models (Queyranne and Ball, 2006; Lan et al., 2008; Birbil et al., 2009; Perakis et al., 2010; Rusmevichientong and Topaloglu, 2012; Gabrel et al., 2014; Liang et al., 2017; Gönsch, 2017). Methods that rely exclusively on historical data without traditional demand forecasting and optimization have also been proposed (van Ryzin and McGill, 2000).

Common revenue management modeling assumptions that came under scrutiny in the robust revenue management papers found in the literature are the functional form of the distribution of demand, deterministic assumption of market fare values used in determining availability despite its uncertainty, decision making under uncertainty with uncertain demand distributions, accuracy of the consumer choice model estimates of the logit coefficients after schedule changes, the functional form of the cost of oversales and spoilage, functional form of the show up rate and accuracy of the assumptions used to estimate spill and unconstrained demand. The outcome of traditional robust revenue management techniques is to produce stable, if often conservative, inventory control recommendations that can result in missed revenue opportunities. Simulation experiments can demonstrate that robust revenue management techniques will always underperform traditional revenue management models. For this reason, deploying robust revenue management techniques has never been a priority for airlines.

The impact of COVID-19 on the airline industry has created a tumultuous period and historical performance characteristics of routes and customers have little or no correlation with future performance. The volatile nature and unpredictability of future outbreaks with infections as observed 
with escalating new cases has caused tremendous fundamental business uncertainty. Flights bookings have literally disappeared in many markets and booking behavior patterns bear little or no resemblance to past behavior. With the COVID-19 pandemic in our midst, historical booking data may not represent the future. What is required is an adaptive robust revenue management approach that does not rely on demand forecasts based on historical data but relies on monitoring key performance indicators in real time to take corrective action. The continuous demand approach to manage inventory controls during this period of high uncertainty and volatility has similarities to the sales and operations (S\&OP) workflow (Palmatier and Crum, 2003) of synchronizing demand, available capacity (supply) and resources for peak performance. The S\&OP workflow is practiced by high tech computer original equipment manufacturers (OEMs), consumer electronics, consumer package goods and the retail industry (Vinod, 2005) verticals. It is an adaptive robust revenue management approach to master uncertainty. It relies less on stable historical demand forecasts but adapts to the current reality using up-to-the-minute monitoring of key performance indicators and reconciliation.

\section{Continuous demand management}

Revenue management serves a central role in an organization. For a typical airline, there are two revenue management functions: strategic (long term) and tactical (short term). Tactical revenue management focuses on the goal of maximizing network revenues with a given schedule and fare structure. Strategic revenue management focuses on formulating a plan for the long-term. Planning for the long-term must consider the marketing plan encompassing flight schedules, fares, group and off-tariff sales practices, distribution methods, passenger handling policies, frequent flyer accrual and redemption programs and advertising. Long-term planning is conducted at the corporate level due to the large number of airline functions that are involved.

For example, consider pre-departure flights. The "displacement rate" measured as the ratio of spillto-date (passengers turned away because the booking class was closed) to the unconstraineddemand-to-date by booking class is an extremely important measure to track on a predeparture basis. When the displacement rate is not increasing along the booking class hierarchy from highest (most valuable booking class) to lowest (deeply discounted booking class), it is obvious that there is a problem, and it serves as an early warning signal to take corrective action leading up to the flight departure date.

Key performance indicators (KPIs) associated with revenue management, like yield, revenue/ask, spoilage, market share, oversales, forecast error and spill rates should be tracked and monitored across organizational silos, given its relevance to the key stake holders in an airline. This end-to-end transparency horizontally (across organizational boundaries) and vertically (within an organizational hierarchy) should be leveraged to enable zero latency in decision making.

For adaptive robust revenue management to work, there needs to be strong collaboration and business process alignment across organizational silos (Vinod, 2021a). This entails the optimal usage of revenue management data (both inputs and derived outputs) for effective decision making across all major functional areas such as network planning and flight scheduling, airline pricing, reservations and inventory control, product distribution, ancillary products and retailing, interactive marketing, loyalty, sales and operations.

Event management supports the orchestration of continuous demand management based on alerts generated from revenue management performance measures. The active management of events serves as a central nervous system for the airline. This requires the calculation of revenue management KPls at distinct levels of aggregation, the frequency with which the KPI's will be monitored and corrective action that should be undertaken with a demand lever or a supply lever. Figure 2 illustrates how events can be established and actively managed.

Examples of demand levers are inventory control actions, pricing actions, promotions, sales incentives and overrides (Vinod, 2021a). Examples of supply levers are capacity changes, change frequency on markets served and entry into new markets. Demand levers are extremely agile and the impact on the KPI's is observed quickly. In contrast, supply levers will be reflected in the KPI's

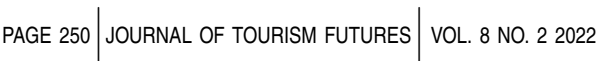


Figure 2 Events and alerts resolution

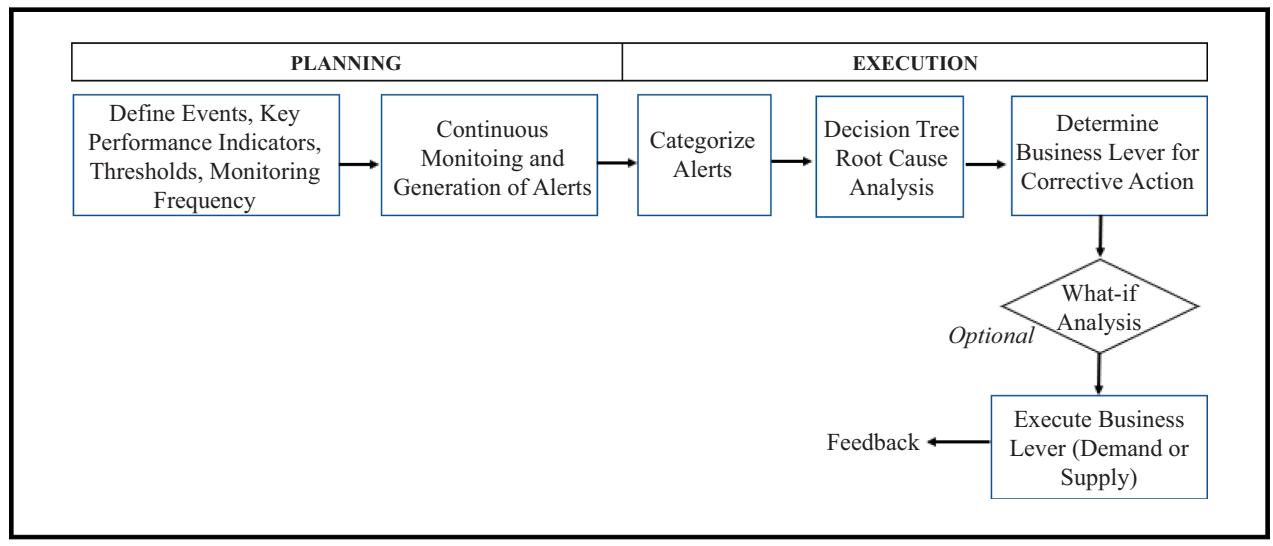

only after a few weeks. Figure 3 illustrates the monitoring process for KPI's. Event identification is followed with the root cause analysis to determine what caused the deviation from the plan and the corrective action that must be taken by invoking a demand lever or supply lever.

Figure 4 illustrates the corrective actions that can be taken to achieve the plan. Each underperforming market entity will have a decision tree that identifies the root causes followed by the identification of the business levers that should be invoked. Figure 4 illustrates the root cause analysis framework for a single KPI (system revenue). Note that the activation of the business lever may lie in different organizations such as pricing, revenue management, sales, capacity planning, etc. A similar decision tree will be required for all KPI's that need to be monitored such as "Yield Below Plan" to ensure consistency in decision making.

The approach outlined in Figures 3 and 4 is vastly different from the traditional revenue management analyst workflow of reviewing a problem window with critical flights and markets to take corrective action. Instead of the traditional bottom-up approach of reviewing individual critical flights and markets in the problem window, a top-down approach is recommended to take corrective action since it is unlikely that historical demand for individual flights and markets will have any bearings on the future state of a post-COVID-19 world.

\section{Conclusions}

Is "COVID zero" achievable? Unlikely, but normal life will return once the pandemic is under control. Let us not forget that influenza, commonly known as the flu, still ranks among the 15 leading causes of death in the United States. It is anticipated that in a post-COVID-19 world, airline business

\section{Figure 3 Event notification and problem identification}

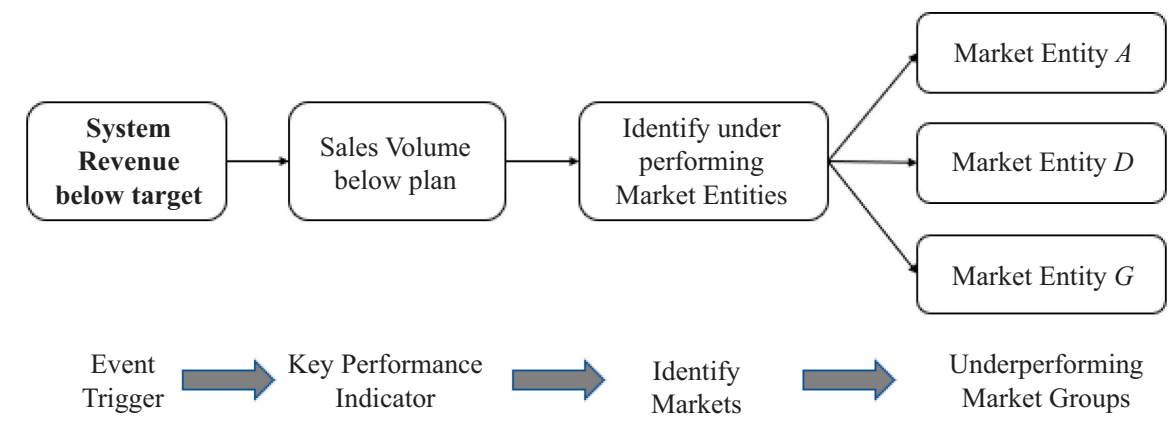

VOL. 8 NO. 22022 |JOURNAL OF TOURISM FUTURES | PAGE 251 


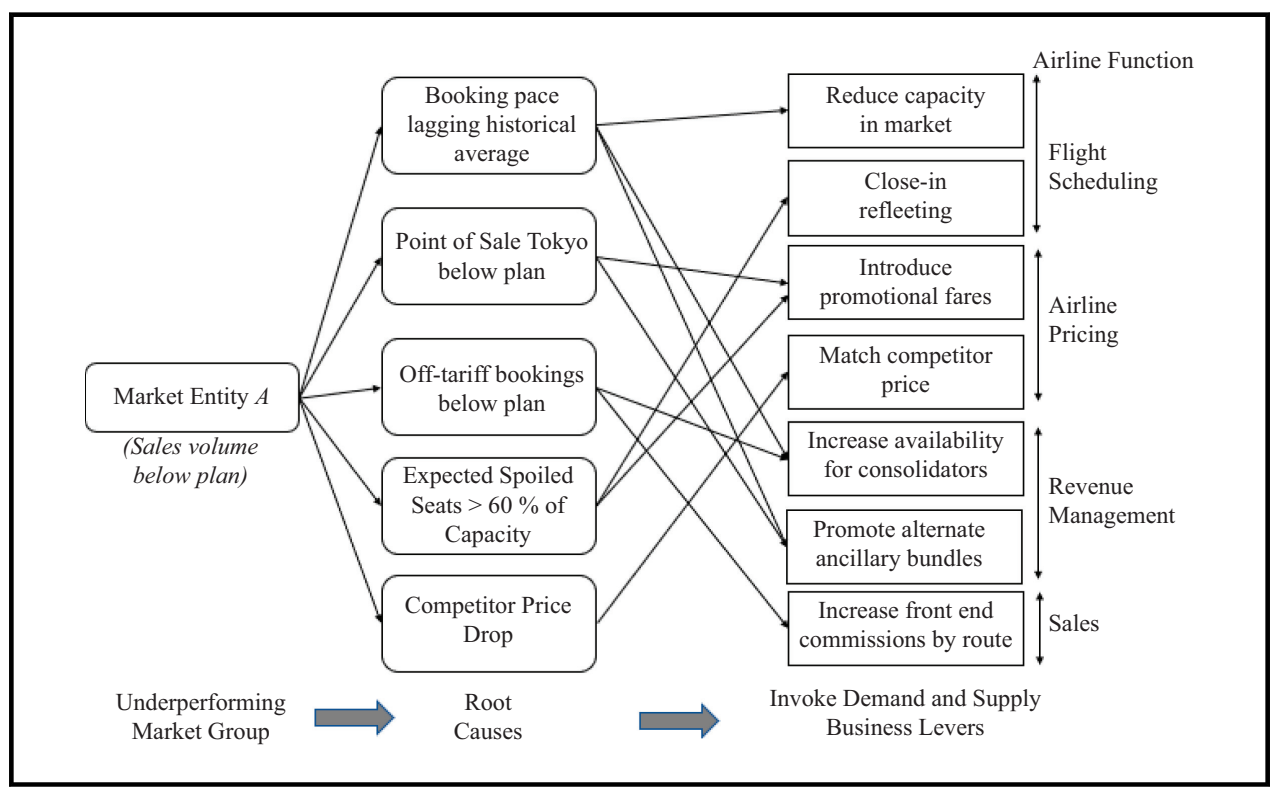

processes will transform to be nimbler and more proactive in making timely decisions at a greater velocity. Planning processes for scheduling, pricing and revenue management will rely more on incremental planning and adjustments to adapt to market conditions. Flight scheduling will rely more on clean sheet scheduling, schedule revisions and close in refleeting to better match supply to demand. The office of the chief financial officer will have a permanent task force to monitor cash flow and come up with innovative solutions to generate cash flow for liquidity. Adaptive robust revenue management workflows will be integrated into traditional revenue management workflows in the future for competitive advantage. The eventual outcome that is anticipated with these initiatives in marketing planning is to enable rapid decision making.

\section{Notes}

1. https://www.aacargo.com/about/writing-the-playbook-american-to-offer-more-than-1000-cargo-onlyflights-september.html

2. Discussion with Jeff Popple, Director of AirVision/Flight Scheduling at Sabre, December 30, 2020. https://www.linkedin.com/pulse/close-in-schedule-changes-jeff-popple/?trackingld =4\%2F\% 2FeXF2nAZzIwHjSTWGwOA\%3D\%3D

\section{References}

Birbil, I., Frenk, J.B.G., Gromicho, J.A.S. and Zhang, S. (2009), "The role of robust optimization in single-leg airline revenue management”, Management Science, Vol. 55 No. 1, pp. 148-163.

Gabrel, V., Murat, C. and Thiele, A. (2014), "Recent advances in robust optimization: an overview", European Journal of Operational Research, Vol. 235 No. 3, pp. 471-483.

Gönsch, J. (2017), "A survey of risk-averse and robust revenue management", European Journal of Operational Research, Vol. 263 No. 2, pp. 337-348.

IATA (2020), Recovery Delayed as International Travel Remains Locked Down, IATA Press Release, July 28, available at: https://www.iata.org/en/pressroom/pr/2020-07-28-02/.

Lan, Y., Gao, H., Ball, M.O. and Karaesman, I. (2008), "Revenue management with limited demand information", Management Science, Vol. 54 No. 9, pp. 1594-1609, doi: 10.1287/mnsc.1080.0859.

Liang, D., Ratliff, R.M. and Remenyi, N. (2017), "Robust revenue opportunity modeling with quadratic programming", Journal of Revenue and Pricing Management, Vol. 16 No. 3, pp. 569-679. 
Palmatier, G.E. and Crum, C. (2003), Enterprise Sales and Operations Planning: Synchronizing Demand, Supply and Resources for Peak Performance, J. Ross Publishing, 1-932159-00-2.

Perakis, G., Roels, G. and Robust Controls for Network Revenue Management (2010), available at: https:// ssrn.com/abstract $=1018518$.

Queyranne, M. and Ball, M.O. (2006), Toward Robust Revenue Management: Competitive Analysis of Online Booking (March 21, 2006), Robert H. Smith School, Research Paper No. RHS 06-021, available at: https:// ssrn.com/abstract $=896547$.

Rattner, N. and Feuer, W. (2021), U.S. Surpasses 500,000 Covid Deaths after Yearlong Battle with Pandemic, CNBC Health and Science, February 22, available at: https://www.cnbc.com/2021/02/22/theus-covid-19-death-toll-has-surpassed-500000.html.

Reed, D. (2021), The 6 Largest U.S. Airlines Lost A Whopping \$35 Billion in 2020, Forbes, January 28, available at: https://www.forbes.com/sites/danielreed/2021/01/28/american-southwest-jetblue-all-reporthuge-fourth-quarter-2020-losses/?sh=75770a957679.

RT Question More (2020), “'Deepest crisis ever': Covid-19's effect on airlines dwarfs 9/11 fallout, says industry", available at: https://www.rt.com/news/484829-coronavirus-airline-industry-crisis/ (accessed 2 April).

Rusmevichientong, P. and Topaloglu, H. (2012), "Robust assortment optimization in revenue management under the multinomial logit choice model", Operations Research, Vol. 60 No. 4, available at: https://people. orie.cornell.edu/huseyin/publications/logit_robust.pdf.

Shapiro, A. (2020), International Travel Could Take until 2024 to Recover from COVID-19, Yahoo Finance, September 17, available at: https://finance.yahoo.com/news/iata-international-travel-2024-to-recover-fromcovid-19-103216023.html.

van Ryzin, G. and McGill, J. (2000), "Revenue management without forecasting or optimization: an adaptive algorithm for determining airline seat protection levels", Management Science, Vol. 46, pp. 760-775.

Vinod, B. (2005), "Retail revenue management and the new paradigm of merchandise optimization", Journal of Revenue and Pricing Management, Vol. 3 No. 4, pp. 358-368.

Vinod, B. (2020a), "The covid-19 pandemic and airline cash flow", Journal of Revenue and Pricing Management, Vol. 19, pp. 228-229.

Vinod, B. (2020b), "How airlines can adapt to survive in a COVID-19 and post COVID-19 era", Presentation at Webinar: Value Based Pricing and Revenue Management in a COVID-19 World, Wellington School of Business and Government.

Vinod, B. (2021a), "An approach to adaptive robust revenue management with continuous demand management in a COVID-19 era", Journal of Revenue and Pricing Management, Vol. 20, pp. 10-14, doi: 10. 1057/s41272-020-00269-9.

Vinod, B. (2021b), The Evolution of Yield Management in the Airline Industry: Origins to the Last Frontier, Springer Nature, 13: 978-3030704230, 10: 3030704238, May 28.

Wood, D. (2021), US Airlines Report Major Financial Losses for 2020, Travel Pulse, available at: https://www. travelpulse.com/news/airlines/us-airlines-report-major-financial-losses-for-2020.html.

\section{About the author}

Ben Vinod is a co-founder and Chief Operating Officer of Charter and Go. He was Chief Scientist and Senior Vice President at Sabre (2008-2020) and Vice President at American Airlines Decision Technologies (1993-1999), responsible for Pricing, Yield Management, and Inventory Control. He is the author of The Evolution of Yield Management in the Airline Industry: Origins to the Last Frontier, published by Springer in May 2021. Ben Vinod can be contacted at: benvinod@yahoo.com

For instructions on how to order reprints of this article, please visit our website: www.emeraldgrouppublishing.com/licensing/reprints.htm Or contact us for further details: permissions@emeraldinsight.com 